\title{
Các yếu tố ảnh hưởng đến việc công bố báo cáo phát triển bền vũng - Trường hợp các doanh nghiệp tại Việt Nam
}

\section{Factors affecting the disclosure of sustainable development report - A case study of Vietnamese enterprises}

\author{
Trịnh Hữu Lực ${ }^{1 *}$, Tăng Thành Phước ${ }^{1}$ \\ ${ }^{1}$ Trường Đại học Bạc Liêu, Việt Nam \\ *Tác giả liên hệ, Email: thluc@blu.edu.vn
}

\section{THÔNG TIN}

DOI: $10.46223 / \mathrm{HCMCOUJS.}$ econ.vi.14.2.490.2019

Ngày nhận: 23/04/2019

Ngày nhận lại: 07/06/2019

Duyệt đăng: 20/06/2019

\section{Tù khóa:}

báo cáo phát triển bền vững, công ty niêm yết, lý thuyết đại diện, lý thuyết tín hiệu, VNR500
TÓM TẮT 
Keywords:

agency theory, listed company, signal theory, sustainable development report, VNR500

report at 143 enterprises from the top 500 largest enterprises listed on the stock market (VNR500). The results show that the firm size, growth opportunities towards enterprises and the sectors have an impact on the publication of sustainable development report. The result is the basis for stakeholders to take appropriate actions to promote the publication of this kind of report in the future.

\section{Giới thiệu}

Báo cáo phát triển bền vững là kênh thông tin hữu ích giúp doanh nghiệp thỏa mãn nhu cầu đa dạng của các đối tượng liên quan về vấn đề kinh tế, môi trường và xã hội. Việc công bố những hoạt động và chiến lược hướng tới phát triển bền vững mang lại những lợi ích cả trong nội bộ lẫn bên ngoài doanh nghiệp. Một mặt các báo cáo này giúp doanh nghiệp nâng cao tính minh bạch, giá trị thương hiệu và danh tiếng (Brown, de Jong, \& Levy, 2009). Mặt khác đây là nguồn thông tin để các doanh nghiệp hiểu rõ hơn về rủi ro và cơ hội, cải thiện các quy trình, hệ thống, giảm chi phí, đảm bảo mối quan hệ giữa các hoạt động tài chính và phi tài chính. Vì vậy, chủ đề báo cáo phát triển bền vững ngày càng thu hút được nhiều sự chú ý từ các doanh nghiệp và các nhà nghiên cứu. Theo Tổ chức Sáng kiến Báo cáo Toàn cầu $(\mathrm{GRI})$, báo cáo phát triển bền vững được các công ty hay tổ chức công bố nhằm thông tin đến các bên liên quan về các tác động kinh tế, môi trường và xã hội mà các công ty hay tổ chức tạo ra trong quá trình hoạt động kinh doanh. Thông tin về tác động kinh tế, môi trường và xã hội đã được các doanh nghiệp phương tây công bố đến các bên liên quan từ những năm 70, tuy nhiên các thông tin này được xem xét và trình bày trong những báo cáo độc lập với nhau (Hahn \& Kühnen, 2013).

Tại Việt Nam, Thông tư số 155/2015/TT-BTC ngày 06/10/2015 do Ủy ban Chứng khoán Nhà nước xây dựng và ban hành nhằm hướng dẫn công bố thông tin trên thị trường chứng khoán đã tích hợp các thông tin về môi trường, xã hội và quản trị công ty vào mẫu báo cáo thường niên. Chính văn bản này đã làm tăng nhận thức của các doanh nghiệp về sự cần thiết của báo cáo phát triển bền vững. Các doanh nghiệp tiến hành công bố báo cáo phát triển bền vững nhằm chứng mình rằng doanh nghiệp đang hoạt động phù hợp với Chiến lược quốc gia về tăng trưởng xanh (Quyết định số 1393/QĐ-TTg) cũng như phù hợp với thông lệ quốc tế về bảo vệ môi trường và duy trì sự ổn định của xã hội. Vì vậy, từ ngày $1 / 1 / 2016$ các doanh nghiệp niêm yết bắt đầu công bố các thông tin liên quan đến sự phát triển bền vững trong báo cáo thường niên. Tuy nhiên mức độ và cách thức công bố thông tin của các doanh nghiệp chưa được như mong đợi. Cụ thể, kết quả nghiên cứu của Pham (2016) cho thấy dù tình hình lập báo cáo phát triển bền vững của doanh nghiệp có tiến triển nhưng mức độ còn sơ sài và không đạt chuẩn. Hay trong Cuộc bình chọn Doanh nghiệp niêm yết năm 2018 do Sở Giao dịch Chứng khoán Thành phố Hồ Chí Minh, Sở Giao dịch Chứng khoán Hà Nội và báo Đầu tư phối hợp tổ chức cho thây đa số các doanh nghiệp lồng ghép nội dung về môi trường và xã hội vào Báo cáo thường niên. Riêng các doanh nghiệp niêm yết công bố báo cáo phát triển bền vững theo chuẩn GRI phiên bản mới nhất với độ tin cậy cao chỉ nằm ở con số "10". Dù vậy, các nghiên cứu tại Việt Nam trong thời gian gần đây về Báo cáo phát triển bền vững lại rất hạn chế. Điển hình có Nguyen (2017) nghiên cứu nhận định, tổng hợp và đề xuất mô hình nghiên cứu trong tương lai hay Tran, Nguyen, và Pham (2018) làm rõ các vấn đề liên quan đến định nghĩa, xu hướng, nội dung cũng như các lý do tại sao phải lập báo cáo phát triển bền vững. Gần đây nhất, Dang, Pham, Tran, và Dang (2018) nghiên cứu về các nhân tố ảnh hưởng đến mức độ công bố thông 
tin trách nhiệm xã hội, phát triển bền vững trên báo cáo thường niên của các doanh nghiệp niêm yết ở Việt Nam. Dù việc công bố báo cáo phát triển bền vững độc lập với báo cáo thường niên mang đến sự tin cậy nhưng đa số doanh nghiệp lại tích hợp các thông tin này vào báo cáo thường niên như đã nói ở trên. Chính vì thế, để có cái nhìn rõ ràng hơn, trong nghiên cứu này, tác giả sẽ làm rõ mức độ ảnh hưởng của các yếu tố đến việc công bố báo cáo phát triển bền vững độc lập với báo cáo thường niên của nhóm 500 doanh nghiệp lớn trên thị trường chứng khoán Việt Nam (VNR500).

\section{Cơ sở lý thuyết}

\section{Định nghĩa sụ bền vĩng của doanh nghiệp}

Theo Aras và Crowther (2009), vẫn còn nhiều tranh cải về khái niệm sự bền vững. Một luồng ý kiến cho rằng sự bền vững chính là sự phát triển bền vững hay ổn định của doanh nghiệp theo thời gian. Luồng ý kiến khác cho rằng, sự bền vững của doanh nghiệp chỉ đến khi chiến lược phát triển của doanh nghiệp có kết hợp các vấn đề về môi trường và xã hội. Chính vì sự không thống nhất trong khái niệm về sự bền vững, một số phân tích về sự bền vững đã không xem xét đầy đủ các khía cạnh của sự bền vững. Bằng chứng là một phân tích sự bền vững tập trung vào hai khía cạnh môi trường và xã hội. Trong khi đó rất ít phân tích sự bền vững có đề cập đến khía cạnh thứ ba - kinh tế. Aras và Crowther (2009) đề xuất mô hình về sự bền vững của doanh nghiệp bao gồm 04 khía cạnh cần quan tâm. Đầu tiên là Ảnh hưởng xã hội (Social influence), đây là khía cạnh nói về ảnh hưởng của các yếu tố xã hội lên doanh nghiệp bao gồm cam kết với xã hội, thỏa thuận với các bên liên quan đến doanh nghiệp. Hai là Tác động môi trường (Environmental impact), chính là tác động của hoạt động kinh doanh lên môi trường xung quanh. Khía cạnh thứ ba là Văn hóa doanh nghiệp (Organisational culture), nói về các mối liên hệ với các bên liên quan bên trong doanh nghiệp như nhân viên và các khía cạnh khác nhau của mối quan hệ với nhân viên. Và cuối cùng là khía cạnh Tài chính (Finance) hay nói cách khác đó chính là thu nhập của doanh nghiệp.

\section{Nhu cầu thông tin tù̀ báo cáo phát triển bền vĩng}

Doanh nghiệp công bố thông tin phát triển bền vững nhằm đáp lại nhu cầu và sự đòi hỏi của xã hội về một doanh nghiệp kinh doanh có trách nhiệm (Frost, Jones, Loftus, \& Van Der Laan, 2005). Những năm 70, xã hội có những thay đổi bất thường từ các tác động của hoạt động kinh doanh của các doanh nghiệp, báo các tác động xã hội đã được các doanh nghiệp công bố nhằm thông tin cho các bên liên quan về những tác động của hoạt động kinh doanh đến tình hình xã hội. Những năm 80 , vấn đồ ô nhiễm môi trường là chủ đề được quan tâm nhiều cho nên các doanh nghiệp công bố báo cáo tác động môi trường thay cho các báo cáo tác động xã hội nhằm thông tin cho cộng đồng biết những tác động của hoạt động kinh doanh lên môi trường xung quanh. Báo cáo tác động xã hội, báo cáo tác động môi trường hay báo cáo phát triển bền vững cùng thể hiện mối liên kết giữa chiến lược phát triển của công ty với sự cam kết về sự phát triển bền vững của nền kinh tế toán cầu trong đó vấn đề xã hội cũng như môi trường được chú trọng bảo vệ và duy trì phát triển ổn định. Theo Hahn và Kühnen (2013), báo cáo phát triển bền vững và báo cáo trách nhiệm xã hội là khái niệm tương đồng với nhau.

\section{Động cơ của việc công bố báo cáo phát triển bền vĩung}

Trong nghiên cứu của Kolk (2004) đã chỉ ra động cơ khiến các công ty công bố hoặc không công bố các báo cáo phát triền bền vững. Lý do các công ty công bố các báo cáo bền vững là: (1) nâng cao khả năng kiểm soát quá trình thực hiện các mục tiêu cụ thể; (2) hỗ trợ 
triển khai chiến lược về môi trường; (3) nâng cao nhận thức về các vấn đề môi trường; (4) chuyển tải thông điệp cho doanh nghiệp; (5) nâng cao tính minh bạch; (6) nâng cao khả năng chuẩn hóa; (7) giấy phép hoạt động; (8) danh tiếng, nâng cao cơ hội phát triển. Trong khi đó, lý do khiến các doanh nghiệp không công bố báo cáo phát triển bền vững là: (1) không chắc chắn về những lợi ích mang lại từ việc công bố thông tin; (2) đối thủ cạnh tranh không công bố thông tin; (3) khách hàng không quan tâm đến; (4) đã có danh tiếng trong việc bảo vệ môi trường; (5) có nhiều cách khác để truyền thông các vấn đề về môi trường; (6) chi phí công bố cao; (7) khó thu thập dữ liệu đồng bộ từ tất cả các hoạt động kinh doanh; (8) có thể làm tổn hại danh tiếng của doanh nghiệp.

Hiện nay, các báo cáo phát triển bền vững chủ yếu được công bố tự nguyện. Vì vậy, các doanh nghiệp linh hoạt trong cung cấp thông tin phát triển bền vững. Báo cáo phát triển bền vững có thể được cung cấp dưới dạng đa hướng hay tích hợp nhưng cũng có thể được cung cấp đơn hướng như báo cáo môi trường, báo cáo trách nhiệm xã hội. Trong phạm vi nghiên cứu này, báo cáo phát triển bền vững là dạng báo cáo phân tích các yếu tố ảnh hưởng đến sự phát triển bền vững của doanh nghiệp bao gồm tác động kinh tế, môi trường và xã hội.

\section{Các lý thuyết sủ̉ dụng}

Công bố hay không công bố thông tin là một trong những quyết định quan trọng đối với doanh nghiệp, bởi kết quả mang lại từ việc này có thể là tích cực, hoặc cũng có thể là tiêu cực. Trên thực tế, hành động công bố hay không công bố các thông tin liên quan đến doanh nghiệp của các nhà quản trị cũng được giải thích bởi một số các lý thuyết nhất định. Đầu tiên là lý thuyết đại diện (Agency theory), lý thuyết này cho rằng việc mâu thuẩn lợi ích giữa một bên là chủ và một bên là người đại diện là điều hiển nhiên. Cho nên về phía chủ sẽ thiết lập những cơ chế cụ thể để kiểm soát các hoạt động cũng như quyền hành của người đại diện, để đảm bảo các hoạt động của người đại diện sẽ phục vụ cho lợi ích của người chủ (Jensen \& Meckling, 1976). Thứ hai là lý thuyết tín hiệu (Signalling theory), lý thuyết này xem việc công bố thông tin là một tín hiệu đưa ra ngoài thị trường để giảm việc bất cân xứng thông tin, tối ưu hóa chi phí tài chính và tăng giá trị của doanh nghiệp (Baiman \& Verrecchia, 1996). Việc này làm cho chi phí tiếp cận nguồn vốn của doanh nghiệp thấp xuống, qua đó làm tăng mức độ đầu tư, kéo theo sự phát triển của nền kinh tế, nhiều việc làm hơn, chất lượng cuộc sống tốt hơn. Thứ ba là lý thuyết chi phí quản lý nhà nước (Political theory), theo lý thuyết này doanh nghiệp sẽ tự nguyện tăng cường việc công bố các thông tin để làm giảm các khoản chi phí liên quan đến thuế, phí cũng như đạt được một số lợi ích nhất định (các khoản trợ cấp hay các hoạt động hỗ trợ của chính quyền). Cuối cùng là lý thuyết chi phí sở hữu, lý thuyết này cho rằng có tồn tại một số chi phí song song với những lợi ích mang lại từ việc công bố thông tin. 2 loại chi phí phổ biến: thứ nhất là tập hợp và công bố thông tin; hai là những chi phí phát sinh từ những thông tin mà đối thủ cạnh tranh và một số bên liên quan tận dụng để gây ảnh hưởng xấu đến công ty. (Không nhất thiết chi phí phải thể hiện bằng tiền - có thể là uy tín, có thể là việc giảm giá trị của công ty...).

\section{Mô hình, phương pháp nghiên cứu và các giả thuyết}

Khi bàn về các yếu tố tác động đến nội dung và hình thức các báo cáo của doanh nghiệp, kết quả của các nghiên cứu trước đây cho thấy quy mô (Ettredge, Richardson, \& Scholz, 2002; Oyelere, Laswad, \& Fisher, 2003; Serrano-Cinca, Fuertes-Callén, \& Gutiérrez-Nieto, 2007), lợi nhuận (Frias-Aceituno, Rodríguez-Ariza, \& Garcia-Sánchez, 2014; Hackston \& Milne, 1996), ngành nghề (Oyelere et al., 2003; Xiaomei, 2004) và cơ hội phát triển (Prado-Lorenzo \& GarciaSanchez, 2010; Prado-Lorenzo, Gallego-Alvarez, \& Garcia-Sanchez, 2009) là 4 biến dự báo 
(predictive variables) được sử dụng nhiều nhất. Dựa vào nội dung của các lý thuyết trên, cùng với việc kế thừa kết quả từ các nghiên cứu trước đây, tác giả lập luận và đề xuất các giả thuyết với các yếu tố có thể tác động đến việc công bố báo cáo phát triển bền vững như sau:

Quy mô công ty ít nhiều có tác động đến việc công bố thông tin. Điều này là do những khác biệt rõ ràng trong đặc điểm của những công ty có quy mô lớn và nhỏ. Trong đó, các doanh nghiệp quy mô lớn kinh doanh nhiều sản phẩm hơn, mạng lưới cung ứng ấn phẩm rộng hơn, cần nhiều vốn hơn, chịu nhiều sức ép hơn từ phía khách hàng, đối tác, ngân hàng và các cơ quan chính quyền. Chính những đặc điểm này tác động đến số lượng cũng như chất lượng của thông tin được công bố.

Dựa trên lý thuyết tín hiệu, với những sức ép kể trên, thì các doanh nghiệp sẽ dùng thông tin như là một tín hiệu phát ra để chứng minh với các bên liên quan về vai trò, vị trí, tiềm năng của mình. Và điều này sẽ dễ dàng mang đến cho doanh nghiệp nhiều cơ hội hơn trong việc tiếp cận nguồn vốn mà mình đang cần trong xã hội. Theo Giner (1995), các thông tin công bố sẽ là tín hiệu để xúc tác mối quan hệ tốt đẹp giữa doanh nghiệp và các chủ đầu tư trong hiện tại, tương lai.

Cùng với những lập luận thông qua các lý thuyết trên, kết quả của một số bài nghiên cứu cũng cho thẩy mối quan hệ cùng chiều giữa quy mô công ty và việc công bố thông tin của doanh nghiệp (García-Sánchez, Rodríguez-Domínguez, \& Gallego-Álvarez, 2011; Gul \& Leung, 2004; Prencipe, 2004). Tương tự, nhóm tác giả cũng mong đợi một mối quan hệ thuận chiều giữa quy mô công ty với việc công bố báo cáo phát triển bền vững nên giả thuyết sau được đưa ra:

\section{triển bền vũng}

H1: Tồn tại mối quan hệ thuận chiều giữa quy mô công ty với việc công bố báo cáo phát

Khi xem xét nội dung của lý thuyết đại diện thì hành vi của các nhà quản lý được dự báo là sẽ công bố nguồn thông tin nhiều và chất lượng hơn cho các đối tượng sử dụng bên ngoài khi lợi nhuận của công ty đạt ở mức kỳ vọng ban đầu. Mục tiêu của việc làm này là để đảm bảo vị trí quản lý mà mình đang nắm giữ cũng như các vấn đề liên quan đến lương thưởng. Tương tự, nếu dựa trên lý thuyết tín hiệu, một doanh nghiệp có lợi nhuận cao thì có động lực nhiều hơn trong việc công bố thông tin. Bởi việc này sẽ mang lại những lợi ích nhất định.

Dù các lý thuyết được xem xét ở trên đều ủng hộ mối quan hệ thuận chiều giữa lợi nhuận và công bố thông tin, trên thực tế vẫn tồn tại những kết quả khác nhau khi nghiên cứu về mối quan hệ này. Trong khi Wagenhofer (1990), Prencipe (2004) đưa ra mối quan hệ nghịch chiều (với lý do các doanh nghiệp khác sẽ nhảy nhiều hơn vào thị trường khi nhìn thấy các thông tin về lợi nhuận cao) thì kết quả trong các bài nghiên cứu của Khanna, Palepu, và Srinivasan (2004); Gul và Leung (2004) và Frias-Aceituno và cộng sự (2014) lại cho thấy mối quan hệ thuận chiều giữa lợi nhuận và vấn đề công bố thông tin. Đặc biệt, có cả những nghiên cứu mà kết quả cho thấy không tồn tại bất kỳ mối quan hệ có ý nghĩa giữa 2 vấn đề trên (Marston \& Polei, 2004; Oyelere et al., 2003). Với những nội dung lập luận trên, nhóm tác giả quyết định kiểm định giả thuyết sau để làm sáng tỏ hơn vấn đề.

H2: Tồn tại mối quan hệ thuận chiều giữa lợi nhuận của công ty với việc công bố báo cáo phát triển bền vũng

Theo Watts và Zimmerman (1978) thì các doanh nghiệp trong cùng một ngành nghề sẽ công bố thông tin với mức độ, số lượng và bản chất giống nhau, nếu có bất kỳ doanh nghiệp nào đi ngược lại với điều này thì sẽ bị đánh giá dưới góc nhìn tiêu cực. Chính áp lực từ các bên là 
động cơ thúc đẩy doanh nghiệp công bố nhiều thông tin hơn. Các thông tin sẽ là cơ sở để đảm bảo lòng tin của người chủ doanh nghiệp yên tâm hơn về cách điều hành hoạt động của người quản lý từ đó làm giảm chi phí đại diện (agency cost) để thiết lập các cơ chế kiểm soát. Các thông tin đó cũng là các thuyết minh, tín hiệu mà những người quản lý muốn gửi đến cộng đồng, xã hội rằng họ đang điều hành doanh nghiệp theo đúng như những mong đợi, chuẩn mực mà mọi người đặt ra, phần nào làm giảm các chi phí hành chính từ cơ quan chính quyền địa phương (Oyelere et al., 2003). Đó cũng chính là nội dung của lý thuyết đại diện và lý thuyết tín hiệu.

Các nghiên cứu trước đây dù có ủng hộ các nội dung lập luận trên (Gul \& Leung, 2004; Oyelere et al., 2003), nghĩa là các doanh nghiệp hoạt động ở các lĩnh vực khác nhau thì việc công bố thông tin sẽ không giống nhau, tuy nhiên vẫn còn tồn tại một số kết quả không đạt mức ý nghĩa (Craven \& Marston, 1999; Larrán Jorge \& Giner, 2002). Cho nên việc kiểm định lại giả thuyết dưới đây sẽ là một cách để hiểu rõ hơn vấn đề.

H3: Tồn tại mối quan hệ thuận chiều giữa ngành nghề mà công ty đang hoạt động với việc công bố báo cáo phát triển bền vũng

Các doanh nghiệp sẽ phải làm sao để tiếp cận nguồn vốn nhanh chóng nhất và với chi phí rẻ nhất. Tất nhiên việc này sẽ không hề dễ dàng, như nội dung của lý thuyết đại diện cho thấy các nhà đầu tư luôn dè dặt với các quyết định cung cấp vốn của mình cho doanh nghiệp, bởi họ sợ rằng các nhà quản lý không tối ưu hóa các kế hoạch kinh doanh phục vụ lợi ích chung mà chỉ đơn thuần nhắm đến việc chiếm đoạt các tài sản của các nhà đầu tư (Bushman \& Smith, 2001). Ý nghĩ này cộng với việc bất cân xứng thông tin giữa 2 bên mang đến những tác động tiêu cực đến việc tiếp cận và tận dụng các cơ hội phát triển của doanh nghiệp.

Tuy nhiên, nếu doanh nghiệp vận dụng lý thuyết tín hiệu để xóa bỏ tình trạng bất cân xứng thông tin và phát đi tín hiệu tốt đẹp về những dự đoán, những phân tích về cơ hội phát triển của các kế hoạch, dự án trong tương lai thì sẽ gặp vấn đề lợi dụng thông tin của các đối thủ cạnh tranh, điều này ít nhiều làm tổn hại đến quyền lực cũng như lợi thế cạnh tranh của doanh nghiệp sau đó (Admati \& Pfleiderer, 2000; Verrecchia, 1983). Trên thực tế, các tác giả khi nghiên cứu về mối quan hệ này vẫn đưa ra các kết quả không giống nhau. Trong khi Prado-Lorenzo và cộng sự (2009) và Prado-Lorenzo và Garcia-Sanchez (2010) ủng hộ mối quan hệ tích cực giữa cơ hội phát triển và công bố thông tin (càng có cơ hội phát triển thì thông tin công bố càng nhiều để giảm sự bất cân xứng thông tin) thì Debreceny, Gray, và Rahman (2002) và Frias-Aceituno và cộng sự (2014) lại không công nhận việc tồn tại mối quan hệ đó. Vì vậy để hiểu rõ hơn, nhóm tác giả kiểm định giả thuyết sau:

H4: Tồn tại mối quan hệ giũa co hội phát triển của công ty với việc công bố báo cáo phát triển bền vĩng

\section{Phương pháp nghiên cứu}

Mô hình và thông tin các biến

$$
\begin{aligned}
& \mathrm{SR}=\beta_{0}+\beta_{1} \mathrm{SIZE}+\beta_{2} \mathrm{PROFITABILITY}+\beta_{3} \mathrm{SECTOR}+\beta_{4} \mathrm{MTB}+\beta_{5} \mathrm{TYPE}+\mu_{\mathrm{i}} \\
& \text { Biến phu thuộc }
\end{aligned}
$$

SUSTAINABLITY REPORT (SR). Đây là biến phụ thuộc phân loại. Tác giả thực hiện khảo sát trên website xem các công ty có công bố báo cáo phát triển bền vững hay không, giá trị nhận được khi lên kết quả khảo sát của biến này chỉ là "Có" (được mã hóa là 1) hoặc "Không" (được mã hóa là 0 ). 


\section{Biến độc lập}

SIZE: quy mô công ty. Được đo bằng logarit của tổng tài sản.

PROFITABILITY: Tỉ số khả năng sinh lợi của tổng tài sản. Đo bằng ROA.

SECTOR: lĩnh vực hoạt động. Sau khi thống kê từ mẫu, tác giả sẽ thực hiện phân loại các ngành nghề hoạt động thuộc 1 trong 2 nhóm, hoặc là nhạy cảm với môi trường, hoặc là ít nhạy cảm với môi trường. Theo các nghiên cứu trước đây, các ngành sau thuộc nhóm nhạy cảm với môi trường: Khai thác mỏ và tài nguyên; Hóa học; Dầu khí; Sản xuất hàng hóa; Công nghiệp giấy; Đồ gỗ (Deegan \& Gordon, 1996; Frost \& Wilmshurst, 2000). Những ngành ngoài nhóm này thuộc nhóm còn lại.

MTB: cơ hội phát triển. Đo bằng tỉ số Giá trị thị trường/Giá trị sổ sách.

TYPE: loại hình doanh nghiệp. Tác giả phân thành 2 nhóm, hoặc có vốn góp của nhà nước, hoặc không có vốn góp của nhà nước. Đây là biến kiểm soát. Chúng ta đưa vào để loại yếu tố gây nhiễu, chứ không kiểm định biến này.

Phương pháp phân tích dữ liệu: Do biến phụ thuộc là loại biến định tính (biến phân loại) với hai lựa chọn (có hoặc không có lập báo cáo phát triển bền vững) nên sẽ sử dụng phương pháp phân tích hồi quy Logistic.

Mẫu và phương pháp thu thập dữ liệu: Từ danh sách VNR500 của công ty Vietnam Report, tác giả lọc lại danh sách các công ty có niêm yết trên các sàn chứng khoán. Với danh sách rút gọn, tác giả tiếp tục thu thập dữ liệu qua các thông tin, các báo cáo công bố trên website của Sơ giao dịch chứng khoán, website của các công ty nằm trong danh sách. Đặc biệt thông tin về việc công ty có công bố báo cáo phát triển bền vững hay không sẽ được thu thập ở mục "công bố thông tin" trên website của chính công ty đó, đây cũng là dữ liệu của biến phụ thuộc trong mô hình. Tất cả dữ liệu là của năm tài chính 2017. Trong quá trình thu thập, các công ty thiếu bất kỳ thông tin nào sẽ bị loại ra (không có nguồn hoặc nguồn không tin cậy). Cuối cùng, bảng số liệu thu thập hoàn thành với 143 công ty chính thức.

\section{Bảng 1}

Thống kê lĩnh vực hoạt động, loại hình doanh nghiệp và số lượng công ty có lập báo cáo phát triển bền vững

\begin{tabular}{lcc}
\hline Biến & N & \% \\
\hline SECTOR & 58 & 40,6 \\
Ít nhạy cảm với môi trường & 85 & 59,4 \\
Nhạy cảm với môi trường & & \\
TYPE & 91 & 63,6 \\
Có vốn nhà nước & 52 & 36,4 \\
Không có vốn nhà nước & & \\
SUSTAINABILITY REPORT & 87 & 60,8 \\
Có lập báo cáo phát triển bền vững & 56 & 39,2 \\
Không lập báo cáo phát triển bền vững
\end{tabular}

Nguồn: Tác giả thống kê từ kết quả thu thập 


\section{Kết quả nghiên cứu}

Mức độ phù hợp của dũ liệu và mô hình:

Dữ liệu được vào xử lý bằng hồi quy nhị phân trên phần mềm SPSS 25. Để đánh giá mức độ phù hợp của mô hình, kiểm định Omnibus được sử dụng. Dựa trên kết quả, ta thấy Sig. $=0,000<0,01$ (Bảng 2 ), điều này chứng minh rằng mối tương quan giữa biến phụ thuộc và các biến độc lập trong mô hình có ý nghĩa thống kê với khoảng tin cậy trên 99\%, hay nói các khác là dữ liệu thu thập hoàn toàn phù hợp với mô hình này.

\section{Bảng 2}

Kết quả kiểm định Omnibus

\begin{tabular}{ccc|c|c}
\hline & Chi bình phương & df & Mức ý nghĩa \\
\hline \multirow{2}{*}{ Bước 1} & 124,641 & 4 &, 000 \\
\cline { 2 - 5 } & Step & 124,641 & 4 &, 000 \\
\hline Block & 124,641 & 4 &, 000 \\
\hline
\end{tabular}

Nguồn: Trích từ kết quả xử lý SPSS

Thêm vào đó, hệ số mức độ giải thích của mô hình ở mức khá cao với Nagelkerke $\mathrm{R}^{2}=$ 0,788 (Bảng 3). Điều này có nghĩa là 78,8\% sự thay đổi của biến phụ thuộc được giải thích bởi 4 biến độc lập trong mô hình, còn lại là do các yếu tố khác nhưng các yếu tố này không đưa vào mô hình nghiên cứu.

\section{Bảng 3}

Kết quả kiểm định mức độ giải thích của mô hình

\begin{tabular}{cc|c|c}
\hline Bước & Giá trị -2 Log likelihood & $\begin{array}{c}\text { Hệ số } \\
\text { Cox \& Snell } \mathbf{R}^{\mathbf{2}}\end{array}$ & $\begin{array}{c}\text { Hệ số } \\
\text { Nagelkerke } \mathbf{R}^{\mathbf{2}}\end{array}$ \\
\hline 1 & 66,825 &, 582 &, 788 \\
\hline
\end{tabular}

Nguồn: Trích từ kết quả xử lý SPSS

Kiểm định các giả thuyết:

Để kiểm định các giả thuyết ở trên, Kiểm định Wald sẽ được thực hiện. Dựa vào bảng kết quả (Bảng 4), ta sẽ xem xét từng biến sau đây:

Thứ nhất là biến SIZE, đây là biến thể hiện cho quy mô của công ty. Nhìn vào bảng kết quả, ta thấy Sig. $=0,001<0,05$, nghĩa là tồn tại mối quan hệ giữa quy mô công ty với việc lập báo cáo phát triển bền vững. Như vậy, chúng ta chấp nhận giả thuyết H1. Với kết quả bảng 4 , mối quan hệ giữa quy mô và việc công bố báo cáo phát triển bền vững là thuận chiều, giống với rất nhiều các nghiên cứu trước đây (Frias-Aceituno et al., 2014; Gul \& Leung, 2004; Marston \& Polei, 2004; Prencipe, 2004). Điều đó có thể được giải thích bởi việc các công ty lớn sẽ bị quan tâm nhiều hơn bởi các bên liên quan nói riêng và xã hội nói chung, đồng nghĩa nhu cầu về thông tin liên quan đến công ty là cao, qua đó tạo một áp lực nhất định đối với việc phải công bố của công ty. 
Thứ hai là biến SECTOR, đại diện cho lĩnh vực mà công ty đang hoạt động. Dựa vào bảng kết quả, ta có Sig. $=0,000<0,05$ nên mối quan hệ giữa lĩnh vực hoạt động của công ty với việc lập báo cáo phát triển bền vững là có ý nghĩa thống kê. Ta chấp nhận giả thuyết H3. Kết quả này khác với nghiên cứu của Craven và Marston (1999) và Larrán Jorge và Giner (2002), nghĩa là lĩnh vực hoạt động có tác động cùng chiều lên việc lập báo cáo phát triển bền vững tại công ty, rõ hơn là doanh nghiệp hoạt động trong lĩnh vực nhạy cảm với môi trường thì có xu hướng nhiều hơn trong việc lập loại báo cáo này. Điều này cũng thống nhất với các lập luận của Gul và Leung (2004) và Oyelere và cộng sự (2003).

Thứ ba, MTB là biến thể hiện cơ hội phát triển của công ty. Mối quan hệ giữa biến này với việc lập báo cáo phát triển bền vững cũng có ý nghĩa thống kê với Sig. $=0,002<0,05$ nên ta chấp nhận giả thuyết $\mathrm{H} 4$. Đây là biến cuối cùng, cũng là biến thứ 3 đạt mức ý nghĩa thống kê trong số 4 biến đưa vào kiểm định các giả thuyết. Khác với kết quả của Prado-Lorenzo và Garcia-Sanchez (2010) và Frias-Aceituno và cộng sự (2014), kết quả từ Bảng 4 cho ta thấy cơ hội phát triển có tác động đến việc lập báo cáo phát triển bền vững, và sự tác động này là cùng chiều, đồng nghĩa với việc lập công ty sẽ có xu hướng lập báo cáo này khi có nhiều cơ hội phát triển trên thị trường.

Và cuối cùng là PROFITABILITY, biến thể hiện khả năng sinh lợi của tổng tài sản qua tỉ số ROA. Với Sig. $=0,192>0,05$ nên đồng nghĩa không tồn tại mối quan hệ giữa lợi nhuận tạo ra của công ty với việc lập báo cáo phát triển bền vững. Do vậy giả thuyết H2 bị bác bỏ. Nhìn lại kết quả bài nghiên cứu của Frias-Aceituno và cộng sự (2014), ta thấy dù yếu tố khả năng sinh lợi của tổng tài sản đạt mức ý nghĩa thống kê, nghĩa là có tác động đến việc công bố các thông tin bền vững nhưng lại rất yếu chỉ ở độ tin cậy $90 \%(\mathrm{Sig} .=0,087)$. Như vậy, dù tạo ra nhiều nguồn lực nhưng các công ty lại không hoặc ít có xu hướng tận dụng các nguồn lực đó để tạo ra các thông tin có lợi cho mình.

\section{Bảng 4}

Kết quả hồi quy nhị phân (Binary regression)

\begin{tabular}{|c|c|c|c|c|c|c|}
\hline & & Hệ số B & S.E. & Đại lượng Wald & df & Mức ý nghĩa \\
\hline \multirow[t]{5}{*}{ Bước 1} & ROA & ,056 &, 043 & 1,703 & 1 & , 192 \\
\hline & SECTOR & 2,854 & ,665 & 18,447 & 1 &, $000 * *$ \\
\hline & SIZE & 1,230 & ,354 & 12,071 & 1 &, $001 *$ \\
\hline & МТB & 1,328 & ,427 & 9,684 & 1 &, $002 *$ \\
\hline & Constant & $-18,225$ & 4,494 & 16,443 & 1 &, 000 \\
\hline
\end{tabular}

Nguồn: Trích từ kết quả xử lý SPSS

\section{Tác động của biến kiểm soát:}

Như đã khẳng định trong phần mô hình nghiên cứu, tác giả đưa biến TYPE - loại hình doanh nghiệp vào với mục đích không phải kiểm định mối quan hệ giữa biến độc lập và biến phụ thuộc. Mà mục tiêu là xem xét các đặc tính khác nhau của biến này (có và không có vốn 
nhà nước) có gây ra các tác động khác nhau lên việc lập báo cáo phát triển bền vững hay không.

\section{Bảng 5}

Kết quả kiểm định Mann-Whitney U

SR

\begin{tabular}{lc}
\hline Chỉ số Mann-Whitney U & 1963,000 \\
\hline Chỉ số Wilcoxon W & 3341,000 \\
\hline Đơn vị lệch chuẩn (Z) & $-2,000$ \\
\hline Mức ý nghĩa quan sát (Asymp. Sig. (2-tailed)) &, 045 \\
\hline
\end{tabular}

Nguồn: Trích từ kết quả xử lý SPSS

Kiểm định Mann-Whitney $\mathrm{U}$ được dùng để kiểm định sự bằng nhau của trung bình hai tổng thể. Cụ thể trong bài này là giữa các công ty có và không có vốn nhà nước. Qua kết quả của Bảng 5 , ta thấy Sig. (2-tailed) =0,045 $<0,05$ nên có thể kết luận rằng có sự khác nhau trong việc lập báo cáo phát triển bền vững giữa các công ty có vốn nhà nước với các công ty không có vốn nhà nước. Nếu dựa vào tình hình hoạt động trong những năm gần đây cũng như sự khác nhau của cơ chế quản lý của 2 loại hình thì điều này hoàn toàn có thể giải thích được. Trong khi các công ty ngoài nhà nước nhạy cảm với những thay đổi của thị trường thì các công ty có vốn nhà nước lại rất chậm chạp trong quá trình đổi mới bởi 2 từ "cơ chế".

\section{Kết luận và hàm ý quản trị}

Theo kết quả phân tích, việc công bố báo cáo phát triển bền vững của các công ty có niêm yết trên các sàn chứng khoán chịu sự tác động của các biến: quy mô của công ty, lĩnh vực mà công ty đang hoạt động và cơ hội phát triển của công ty. Biến khả năng sinh lợi của tổng tài sản ROA không có sự tác động đến việc công bố báo cáo phát triển bền vững. Ngoài ra, việc lập báo cáo phát triển bền vững giữa các công ty có vốn nhà nước với các công ty không có vốn nhà nước cũng có sự khác nhau. Những kết quả này phần nào cho thấy việc công bố báo cáo phát triển bền vững sẽ giúp doanh nghiệp đạt được sự thừa nhận từ bên ngoài, chiếm được niềm tin của công chúng và nhà đầu tư về sự phát triển bền vững của doanh nghiệp. Đối với nội bộ doanh nghiệp, công bố báo cáo này giúp doanh nghiệp kiểm soát và góp phần làm giảm chi phí, nhấn mạnh mối quan hệ giữa hoạt động tài chính và hoạt động phi tài chính giúp doanh nghiệp lập chiến lược nâng cao giá trị thương hiệu. Đối với bên ngoài doanh nghiệp, công bố báo cáo phát triển bền vững giúp doanh nghiệp xây dựng được niềm tin, tiếp cận người tiêu dùng, góp phần quảng bá thương hiệu của mình. Bên cạnh đó còn giúp doanh nghiệp truyền tải các thông tin đến với các cổ đông, nhà đầu tư và cơ quan quản lý. Đây là cơ sở để các nhà quản lý doanh nghiệp có thêm động lực trong việc công bố báo cáo phát triển bền vững trong thời gian tới. Cùng với đó là nguồn thông tin để các cơ quan Nhà nước có chính sách phù hợp trong việc thúc đẩy các doanh nghiệp công bố báo cáo phát triển bền vững.

Nghiên cứu này cũng tồn tại một số hạn chế cần được xem xét trong tương lai. Cỡ mẫu của bài nghiên cứu chỉ tập trung vào các doanh nghiệp có niêm yết trên thị trường chứng khoán trong danh sách VNR500 của công ty Vietnam Report có công bố đầy đủ thông tin, do đó tính khái quát chưa cao. Ngoài ra, với các lý thuyết đề cập phía trên thì số lượng biến độc lập đưa vào bài nghiên cứu là còn hạn chế, qua đó ảnh hưởng phần nào đến việc đánh giá một cách đầy đủ tác động lên biến phụ thuộc (việc lập báo cáo phát triển bền vững). Chính vì vậy, các nghiên 
cứu trong tương lai có thể mở rộng thêm các biến tác động đến việc lập báo cáo phát triển bền vững như mức độ tập trung (biểu thị mức độ cạnh tranh hay độc quyền trong lĩnh vực công ty đang hoạt động) trong ngành mà công ty đang hoạt động với việc lập báo cáo phát triển bền vững, hay mở rộng thêm đối tượng là các doanh nghiệp kinh doanh trong cùng lĩnh vực xem việc lập báo cáo phát triển bền vững này chịu sự tác động như thế nào. Thậm chí có thể dùng phương pháp nghiên cứu định tính để xem xét vấn đề, bởi phương pháp này sẽ phân tích và đào sâu hơn các thông tin phục vụ quá trình ra quyết định của các nhà quản lý đối với việc có lập và công bố hay không báo cáo phát triển bền vững của doanh nghiệp.

\section{Tài liệu tham khảo}

Admati, A. R., \& Pfleiderer, P. (2000). Forcing firms to talk: Financial disclosure regulation and externalities. The Review of Financial Studies, 13(3), 479-519.

Aras, G., \& Crowther, D. (2009). Corporate sustainability reporting: A study in disingenuity? Journal of Business Ethics, 87(1), 279-288.

Baiman, S., \& Verrecchia, R. E. (1996). The relation among capital markets, financial disclosure, production efficiency, and insider trading. Journal of Accounting Research, 34(1), 1-22.

Brown, H. S., de Jong, M., \& Levy, D. L. (2009). Building institutions based on information disclosure: Lessons from GRI's sustainability reporting. Journal of Cleaner Production, 17(6), 571-580.

Bushman, R. M., \& Smith, A. J. (2001). Financial accounting information and corporate governance. Journal of Accounting and Economics, 32(1/3), 237-333.

Craven, B. M., \& Marston, C. L. (1999). Financial reporting on the Internet by leading UK companies. European Accounting Review, 8(2), 321-333.

Dang, H. N., Pham, D. T. H., Tran, D. T., \& Dang, C. V. (2018). Các nhân tố ảnh hưởng đến mức độ công bố thông tin trách nhiệm xã hội, phát triển bền vũng của các doanh nghiệp

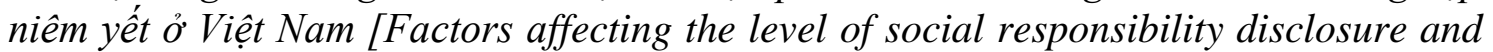
sustainable development of listed companies in Vietnam] . Paper presented at the Nghiên cứu và đào tạo Kế toán, Kiểm toán, Trường Đại học Công nghiệp Hà Nội, Hanoi, Vietnam.

Debreceny, R., Gray, G. L., \& Rahman, A. (2002). The determinants of Internet financial reporting. Journal of Accounting and Public Policy, 21(4/5), 371-394.

Deegan, \& Gordon, B. (1996). A study of the environmental disclosure practices of Australian corporations. Accounting and Business Research, 26(3), 187-199.

Ettredge, M., Richardson, V. J., \& Scholz, S. (2002). Dissemination of information for investors at corporate Web sites. Journal of Accounting and Public Policy, 21(4/5), 357-369.

Frias-Aceituno, J.-V., Rodríguez-Ariza, L., \& Garcia-Sánchez, I. M. (2014). Explanatory factors of integrated sustainability and financial reporting. Business Strategy and the Environment, 23(1), 56-72. 
Frost, G. R., \& Wilmshurst, T. D. (2000). The adoption of environment-related management accounting: An analysis of corporate environmental sensitivity. Accounting Forum, 24(4), 344-365.

Frost, G. R., Jones, S., Loftus, J., \& Van Der Laan, S. (2005). A survey of sustainability reporting practices of Australian reporting entities. Australian Accounting Review, $15(35), 89-96$.

García-Sánchez, I. M., Rodríguez-Domínguez, L., \& Gallego-Álvarez, I. (2011). Corporate governance and strategic information on the Internet: A study of Spanish listed companies. Accounting, Auditing \& Accountability Journal, 24(4), 471-501.

Giner, S. (1995). Civil society and its future. In J. A. Hall (Ed.), Civil society: Theory, history, comparison (pp. 305-314). Cambridge, UK: Polity Press.

Gul, F. A., \& Leung, S. (2004). Board leadership, outside directors' expertise and voluntary corporate disclosures. Journal of Accounting and Public Policy, 23(5), 351-379.

Hackston, D., \& Milne, M. J. (1996). Some determinants of social and environmental disclosures in New Zealand companies. Accounting, Auditing \& Accountability Journal, 9(1), 77-108.

Hahn, R., \& Kühnen, M. (2013). Determinants of sustainability reporting: A review of results, trends, theory, and opportunities in an expanding field of research. Journal of Cleaner Production, 59, 5-21.

Jensen, M. C., \& Meckling, W. H. (1976). Theory of the firm: Managerial behavior, agency costs and ownership structure. Journal of Financial Economics, 3(4), 305-360.

Jorge, M. L., \& Giner, B. (2002). The use of the Internet for corporate reporting by Spanish companies. The International Journal of Digital Accounting Research, 2(1), 53-82.

Khanna, T., Palepu, K. G., \& Srinivasan, S. (2004). Disclosure practices of foreign companies interacting with US markets. Journal of Accounting Research, 42(2), 475-508.

Kolk, A. (2004). A decade of sustainability reporting: Developments and significance. International Journal of Environment and Sustainable Development, 3(1), 51-64.

Marston, C., \& Polei, A. (2004). Corporate reporting on the Internet by German companies. International Journal of Accounting Information Systems, 5(3), 285-311.

Nguyen, V. T. X. (2017). Mô hình nghiên cưu về các nhân tố ảnh hưởng đến báo cáo phát triển bền vĩng [Research model on factors affecting sustainability reporting] . Retrieved October 20, 2018, from Tạp chí Công thương website: http://www.tapchicongthuong.vn/bai-viet/mo-hinh-nghien-cuu-ve-cac-nhan-to-anhhuong-den-bao-cao-phat-trien-ben-vung-47091.htm

Oyelere, P., Laswad, F., \& Fisher, R. (2003). Determinants of Internet financial reporting by New Zealand companies. Journal of International Financial Management \& Accounting, 14(1), 26-63.

Pham, H. T. M. (2016). Vai trò của báo cáo phát triển bền vũng vói doanh nghiệp Việt trong bối cảnh hội nhập [The role of sustainable development reporting with Vietnamese businesses in the integration context] . Retrieved October 22, 2018, from Tạp chí Tài 
chính website: http://tapchitaichinh.vn/tai-chinh-kinh-doanh/tai-chinh-doanhnghiep/vai-tro-cua-bao-cao-phat-trien-ben-vung-voi-doanh-nghiep-viet-trong-boi-canhhoi-nhap-110790.html

Prado-Lorenzo, J.-M., \& Garcia-Sanchez, I.-M. (2010). The role of the board of directors in disseminating relevant information on greenhouse gases. Journal of Business Ethics, 97(3), 391-424.

Prado-Lorenzo, J.-M., Gallego-Alvarez, I., \& Garcia-Sanchez, I.-M. (2009). Stakeholder engagement and corporate social responsibility reporting: The ownership structure effect. Corporate Social Responsibility and Environmental Management, 16(2), 94-107.

Prencipe, A. (2004). Proprietary costs and determinants of voluntary segment disclosure: Evidence from Italian listed companies. European Accounting Review, 13(2), 319-340.

Serrano-Cinca, C., Fuertes-Callén, Y., \& Gutiérrez-Nieto, B. (2007). Online reporting by banks: A structural modelling approach. Online Information Review, 31(3), 310-332.

Tran, H. T., Nguyen, T. T., \& Pham, P. H. (2018). Báo cáo bền vĩng của doanh nghiẹp [Business sustainability reports] . Retrieved October 25, 2018, from Tạp chí Kinh tế Đối ngoại website: http://tracuutapchi.ftu.edu.vn/index.php/tcqlktqt/article/view/239/233

Verrecchia, R. E. (1983). Discretionary disclosure. Journal of Accounting and Economics, 5(1), 179-194.

Wagenhofer, A. (1990). Voluntary disclosure with a strategic opponent. Journal of Accounting and Economics, 12(4), 341-363.

Watts, R. L., \& Zimmerman, J. L. (1978). Towards a positive theory of the determination of accounting standards. Accounting Review, 53(1), 112-134.

Xiaomei, L. (2004). Theory and practice of environmental management accounting. International Journal of Technology Management \& Sustainable Development, 3(1), 47-57. 